\title{
Impacto de la mastectomía sobre la vida sexual y emocional de las mujeres atendidas por un servicio de salud del norte de Minas Gerais
}

\author{
Impact of mastectomy on the sexual and emotional life of women \\ attended by a health service north of Minas Gerais
}

\section{Repercussões da mastectomia na vida sexual e afetiva de mulheres assistidas por um serviço de saúde do norte de Minas Gerais}

Patrick Leonardo Nogueira da Silva ${ }^{1}$, Larissa Martins Silva ${ }^{2}$;

Mariley Simões de Souza ${ }^{3}$; Carolina dos Reis Alves ${ }^{4}$

${ }^{1}$ Enfermeiro, Especialista em Saúde da Família, Universidade Estadual de Montes Claros/UNIMONTES, Montes Claros (MG), Brasil.E-mail: patrick_mocesp70@hotmail.com

${ }^{2-3}$ Acadêmica de Enfermagem, Faculdade Santo Agostinho/FASA, Montes Claros (MG), Brasil.

${ }^{4}$ Enfermeira, Professora Mestre e Doutora em Ciências da Saúde do Departamento de Enfermagem das Faculdades Santo Agostinho/FASA, Montes Claros (MG), Brasil.

Cómo citar este artículo en edición digital: Silva, P.L.N., Silva, L.M., Souza, M.S., \& Alves, C.R. (2017). Impacto de la mastectomía sobre la vida sexual y emocional de las mujeres atendidas por un servicio de salud del norte de Minas Gerais. Cultura de los Cuidados (Edición digital), 21(49). Recuperado de http://dx.doi.org/10.14198/cuid.2017.49.05

Correspondência: Patrick Leonardo Nogueira da Silva - Universidade Estadual de Montes Claros/UNIMONTES, Centro de Ciências Biológicas e da Saúde/CCBS, Avenida Dr. Ruy Braga, S/N - Vila Mauriceia, Montes Claros - MG, 39401-089.

Correo electrónico: patrick_mocesp70@hotmail.com

Recibido: 10/02/2017; Aceptado: 12/05/2017

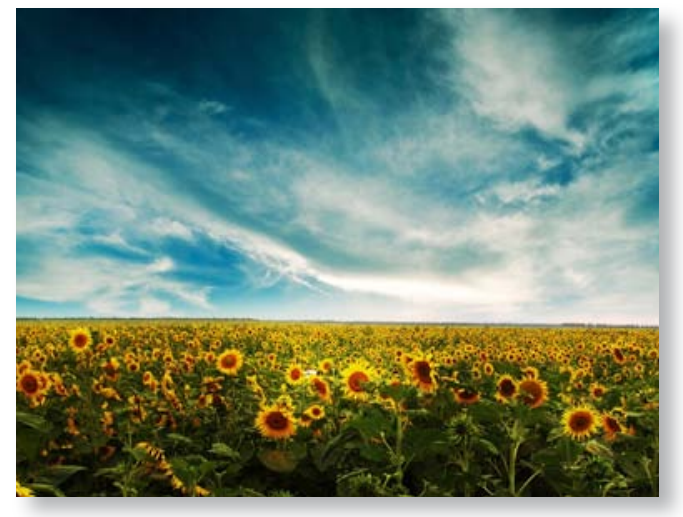

ABSTRACT

This study aims to understand the impact of mastectomy on the sexual and emotional life of women receiving care at a health facility in northern Minas Gerais. This is a descriptive, exploratory study with a qualitative approach, conducted with 12 women in the radiotherapy department of a hospital. We used a not structured interview for data collection. Data were recorded and fully transcribed for further categorization and analysis. Data processing was done through content analysis. It was evident that after radical mastectomy, sexual and emotional life of women is committed by both the physical effects of treatment, such as the psychosocial consequences, such as the construction of female identity, self-image and how to understand others the sighted . It is concluded that there are significant changes in the lives of these women, but the removal of the breast means the removal of a problem and the desire to be cured is greater than losing a breast.

Keywords: Breast neoplasms, Mastectomy radical, sexuality, phenomenology.

\section{RESUMEN}

Este estudio tiene como objetivo comprender el impacto de la mastectomía sobre la vida sexual y emocional de las mujeres que reciben 
atención en un centro de salud en el norte de Minas Gerais. Se trata de un estudio descriptivo, exploratorio con enfoque cualitativo, realizado con 12 mujeres en el departamento de radioterapia de un hospital. Se utilizó una entrevista no estructurada para la recolección de datos. Los datos fueron registrados y totalmente transcritas para su posterior clasificación y análisis. El procesamiento de datos se realiza a través de análisis de contenido. Era evidente que después de la mastectomía radical, la vida sexual y emocional de las mujeres se ha comprometido tanto por los efectos físicos del tratamiento, tales como las consecuencias psicosociales, tales como la construcción de la identidad femenina, la propia imagen y la forma de entender a los demás los videntes . Se concluye que hay cambios significativos en la vida de estas mujeres, pero la extirpación de la mama: la eliminación de un problema y el deseo de curarse es mayor que la pérdida de un seno.

Palabras clave: Neoplasias de la mama, mastectomía radical, sexualidad, fenomenología.

\section{RESUMO}

O presente estudo objetiva compreender o impacto da mastectomia na vida sexual e afetiva de mulheres assistidas em um serviço de saúde do norte de Minas Gerais. Trata-se de um estudo descritivo, exploratório, com abordagem qualitativa, realizada com $12 \mathrm{mu}$ lheres no setor de radioterapia de uma instituição hospitalar. Utilizou-se uma entrevista não estruturada para a coleta dos dados. Os dados foram gravados e transcritos na íntegra para posterior categorização e análise. $\mathrm{O}$ tratamento dos dados se deu por meio de Análise de Conteúdo. Evidenciou-se que após a mastectomia radical, a vida sexual e afetiva das mulheres é comprometida, tanto pelos efeitos físicos do tratamento, como pelas consequências psicossociais, a exemplo da construção da identidade feminina, da autoimagem e de como entendem que os outros as enxergam. Conclui-se que ocorrem mudanças significativas na vida dessas mulheres, porém a retirada da mama significa a retirada de um problema e a vontade de estar curada é maior do que se perder uma mama.

Palavras-chave: Neoplasias da mama, mastectomia radical, sexualidade, fenomenologia.

\section{INTRODUÇÃO}

O câncer de mama é o tipo oncológico mais prevalente na população feminina (Ferlay et al., 2010). Apresenta grande importância quanto à sua mortalidade, com 23\% (1,38 milhões) do total de casos novos por ano (Jemal, Siegel, Xu, \& Ward, 2010). No Brasil, excluídos os tumores de pele não melanoma, o câncer de mama também é o mais incidente em mulheres de todas as regiões, exceto na região norte, onde o câncer do colo do útero (CCU) ocupa a primeira posição. Para o ano de 2012, foram estimados 52.680 casos novos, que representam uma taxa de incidência de 52,5 casos por 100.000 mulheres (Instituto Nacional do Câncer [Inca], 2011; Silva \& Hortale, 2012).

Políticas públicas nessa área vêm sendo desenvolvidas no Brasil desde meados dos anos 80 e foram impulsionadas pelo Programa Viva Mulher, em 1998. O controle do câncer de mama foi reafirmado como prioridade no plano de fortalecimento da rede de prevenção, diagnóstico e tratamento do câncer, lançado pela presidente da República, em 2011. É considerada uma patologia de prognóstico bom, porém é a principal em relação aos casos de 
óbito entre as mulheres, muito provavelmente em função de sua detecção tardia (Inca, 2009).

Além das complicações que qualquer adoecimento comporta (ruptura do corpo saudável, incerteza quanto ao tratamento, possibilidade de recorrência, quebra da rotina diária, encontro com a finitude da vida, sensação de impotência, etc.), esse tipo de câncer é um dos mais receosos pelas mulheres devido aos efeitos psicológicos da amputação parcial ou total da mama, órgão corporal carregado de sensualidade e de significações ligadas à sexualidade e ao desempenho da maternidade (Adachi, Ueno, Fujioka, Fujitomi, \& Ueo, 2007; Sebastián, Manos, Bueno, \& Mateos, 2007; Filgueiras et al., 2007; Cantinelli et al., 2006).

$\mathrm{O}$ adoecimento pelo câncer de mama e seu tratamento geram sérias consequências que podem ser temporárias ou permanentes na vida da mulher. A cirurgia mamária seja ela conservadora ou não, mesmo acompanhada da reconstrução mamária pode ser vivenciada de modo traumático pela mulher, sendo considerada uma mutilação, dependendo da importância dada pela mulher à imagem corporal (Duarte \& Andrade, 2003).

Desde a puberdade até a idade adulta, a mama representam feminilidade, erotismo, sensualidade e sexualidade, constituindo se assim como símbolo da identidade da mulher (Duarte \& Andrade, 2003). Desta forma, o câncer de mama carrega os tabus de uma doença chamada maldita, possível causadora de desfiguração de partes do corpo e até do próprio atrativo sexual além do sofrimento ocasionado pelo tratamento prolongado (Inca, 2011).

A mastectomia constitui-se em uma intervenção cirúrgica altamente traumatizante. Tem uma representação simbólica muito forte, sendo encarada pela mulher, muitas vezes, como uma agressão, já que promove a castração de uma parte do seu corpo - a mama. A sua retirada pode possibilitar o aparecimento de sentimentos de perda que, possivelmente, refletirá na sua identidade feminina. Com a realização deste procedimento, a imagem corporal da mulher se modifica radicalmente, na maioria das vezes, sem um preparo suficiente para se adaptar à sua nova imagem (Amâncio \& Costa, 2007).

A mastectomia surgiu no final do século XIX desde então, é utilizada como uma das modalidades cirúrgicas para o tratamento do câncer de mama (Duarte \& Andrade, 2003). Julga-se um procedimento extremamente agressivo e traumático, a mastectomia radical, vem sendo substituída atualmente por cirurgias mais conservadoras, como a quadrandectomia (remoção de cerca de um quarto da mama) e a lumpectomia (remoção do tumor e de pequena região circunvizinha), desde que o contexto clínico da paciente seja favorável à realização dessas modalidades cirúrgicas. Nessa circunstância, a escolha do método terapêutico a ser adotado, que certamente trará alguma repercussão na vida da mulher, dependerá de vários fatores, tais como localização e tamanho do tumor, análise da mamografia, disponibilidade dos serviços de saúde e modo como a paciente lida com a mama afetada.

Apesar de ser um conceito complexo, cuja definição pode produzir interpretações de lógica extremamente simples e ambíguo, considera-se a imagem corporal como a representação mental que se tem do próprio corpo (Sánchez, 2010; Santos \& Sawaia, 2000). O termo imagem, nesse caso, não se limita ao sentido específico da visão, mas engloba as vivências afetivas, sociais e fisiológicas que influenciam a forma como o sujeito se percebe. Portanto, trata-se de um processo multidimensional e, 
sobretudo, dinâmico (Moreira \& Canavarro, 2010; Sabiston et al., 2010; McGaughey, 2006).

Portanto, o presente estudo objetivou compreender o impacto da mastectomia na vida sexual e afetiva de mulheres assistidas em um serviço de saúde do norte de Minas Gerais.

\section{MATERIAL E MÉTODO}

Trata-se de um estudo descritivo, exploratório, com abordagem qualitativa, realizada no setor de radioterapia do Hospital Santa Casa de Misericórdia de Montes Claros, Minas Gerais (MG), com 12 mulheres na qual foram submetidas à cirurgia de mastectomia radical.

Foram adotados os seguintes critérios de inclusão para participação na pesquisa: mulheres submetidas ao procedimento de mastectomia radical. Foram excluídas do estudo: mulheres submetidas à mastectomia parcial (quadrantectomia). A coleta de dados ocorreu no primeiro semestre de 2013, especificamente nos meses de março e abril.

A participação dos entrevistados se deu mediante a assinatura do termo de consentimento livre e esclarecido (TCLE). Antes de iniciar a coleta dos dados, informaram-se aos participantes a justificativa e os objetivos da pesquisa, bem como o direito de não participar ou desistir a qualquer momento, sem que isso significasse qualquer prejuízo ao entrevistado. Garantiram-se a privacidade e o anonimato das informações coletadas, assegurados pela substituição dos nomes dos entrevistados por pseudônimos, sendo esses nomes de flores.

A coleta se deu por meio da gravação individual dos depoimentos das participantes. Foi utilizado um gravador seguido de um roteiro não estruturado na qual os depoimentos foram transcritos na íntegra e categorizados em seguida. Foram delineadas seis categorias de estudo, sendo elas: "Perda da mama: sentimentos após a mastectomia radical"; "Percepção da mulher sobre o seu corpo após a cirurgia"; "Mudança na vida afetiva e sexual: sentimentos e percepções"; "Perda da mama: impacto da cirurgia na rotina trabalhista da mulher"; "Repercussão e representação da família na vida da mulher mastectomizada"; "Quimioterapia: enfrentamento da mulher na superação da doença"; e "Conforto espiritual".

Ancorando-se nestas informações, foi realizada a leitura dos discursos e, na leitura final, destacadas as figuras e os temas, codificando-os e recortando-os a fim de, agrupa-los em áreas temáticas, o que possibilitou a construção de categorias. O método utilizado para análise dos dados foi a Análise de Conteúdo (Bardin, 2010), definida como um conjunto de técnicas de análise das comunicações que usa procedimentos sistemáticos de descrição do conteúdo das mensagens em três etapas: pré-análise; exploração do material; tratamento dos resultados, inferência e interpretação.

Foram respeitados os preceitos éticos da Resolução n 466/2012 do Conselho Nacional de Saúde (CNS) na qual regulamenta a pesquisa envolvendo seres humanos. O projeto de pesquisa foi apreciado e aprovado pelo Comitê de Ética em Pesquisa da Universidade Estadual de Montes Claros (CEP UNIMONTES), por meio da Plataforma Brasil, com o Parecer Consubstanciado $n^{\circ}$ 174.316/2012.

\section{RESULTADOS E DISCUSSÃO}

\section{Caracterização das mulheres}

Observaram-se mulheres com idade entre 30 e 65 anos, das quais nove eram multíparas; cinco tinham companheiro; três exerciam atividade remunerada na qual tiveram que parar temporariamente de trabalhar para realizar o tratamento; duas tinham história de câncer de mama em parentes de primeiro grau (mãe), uma em segundo grau (avó) e as demais desconhecem; todas foram submetidas à mastec- 
tomia radical; a maior parte estava em tratamento radioterápico (Quadro 1).

Quadro $1 \square$ Perfil socioecon $\square$ mico das mulheres entrevistadas. Montes Claros (MG), 2013.

\begin{tabular}{|c|c|c|}
\hline Vari $\square$ veis & $\mathrm{n}=12$ & $\%$ \\
\hline \multicolumn{3}{|l|}{ Faixa et $\lceil$ ria } \\
\hline $30-45$ anos & 07 & 58,3 \\
\hline $45-65$ anos & 05 & 41,7 \\
\hline \multicolumn{3}{|l|}{ Quantidade de filhos } \\
\hline Nul paras (nenhum filho) & 02 & 16,6 \\
\hline Prim paras (01 filho) & 01 & 8,4 \\
\hline Mult paras ( $\geq 02$ filhos) & 09 & 75 \\
\hline \multicolumn{3}{|l|}{ Estado civil } \\
\hline Solteira & 07 & 58,3 \\
\hline Casada/Uni $₫$ est $₫$ vel & 05 & 41,7 \\
\hline \multicolumn{3}{|l|}{ Exerce atividade remunerada } \\
\hline Sim & 03 & 25 \\
\hline $\mathrm{N} \rightleftharpoons$ & 09 & 75 \\
\hline \multicolumn{3}{|c|}{ Hist $\square$ rico de c $\square$ ncer de mama na fam lia } \\
\hline Parente de $1 \sqsubset$ grau & 02 & 16,6 \\
\hline Parente de $2 \sqsubset$ grau & 01 & 8,4 \\
\hline Desconhece & 09 & 75 \\
\hline \multicolumn{3}{|l|}{ Submiss $\triangle^{\wedge} \wedge$ mastectomia } \\
\hline Parcial & 00 & 00 \\
\hline Radical & 12 & 100 \\
\hline \multicolumn{3}{|l|}{ Tipo do tratamento } \\
\hline Quimioterapia & 02 & 16,6 \\
\hline Radioterapia & 06 & 50 \\
\hline Conclus $\square$ o do tratamento & 04 & 33,4 \\
\hline
\end{tabular}

\section{Perda da mama: sentimentos após a mastec- tomia radical}

$\mathrm{Na}$ mulher mastectomizada predominam sentimentos negativos como o medo do desconhecido e da morte, rejeição, culta e a perda do sentido da vida associado a mudanças em decorrência do processo cirúrgico (Jesus \& Lopes, 2003). Nesse sentido, os depoimentos das participantes destacam que:

"Eu, eu sinto assim moça, assim, sei lá, assim, sinto assim, uma diferença no meu, no meu corpo, eu fiquei assim, as- sim como eu sentir depressão né! Com a cabeça ruim [...]". (Tulipa)

"Mudou tudo, pra pior, pra pior [...] Eu não esperava que me fizesse à cirurgia total. Então foi uma surpresa que eu entrei até em depressão". (Flor de Liz)

"No começo tive uma cisma, achei que ia morrer, fiquei muito preocupada com a mama e com medo de ficar sem cabelo, porém após a cirurgia ocorreu tudo bem". (Lírio)

Esses resultados reforçam que o diagnóstico do câncer de mama aliada mastectomia resultam em uma experiência repleta de temor para as mulheres, pois a maior parte delas quando recebe o diagnóstico sente-se angustiada, insegura e preocupada com o desenvolvimento da doença em seu corpo e o tratamento, bem como com os efeitos colaterais e a possibilidade ou não de sobrevida (Barbosa, Ximenes, \& Pinheiro, 2004).

Porém, algumas mulheres enfatizaram a ausência de mudanças após a mastectomia, uma vez que a noticia da cirurgia representou um alívio, pois, as mesmas estariam retirando do seu corpo um problema.

"Aceitei numa boa, pois não tinha outro jeito. Ela significou a minha vida, poupou a minha”. (Jasmim)

"Não, não mudou de jeito nenhum. Porque continua a mesma coisa, porque eu acho assim, se eu mudasse alguma coisa eu teria entrado em depressão". (Rosa)

"Não, não, mudou nada, foi nada." (Margarida)

"Não mudou muita coisa não, minha vida continua a mesma coisa [...]". (Begônia)

"Então, eu não acho diferença no corpo porque eu não tenho não só essa cirurgia, eu já tirei vesícula, tirei o útero, 
eu já to muito bem e acho que vou precisar tirar a outra mama, porque a outra também tem nódulo". (Gerânio)

Estudo realizado por Amâncio e Costa (2007) destacou também reações de aceitação da mastectomia, embora estivessem relacionadas ao fato de não haver outra condição para atingir a cura do câncer. Vale ressaltar que, tanto no diagnóstico quanto no momento da retirada da mama, o apoio dos familiares e dos companheiros das mulheres com câncer de mama foi relevante para ausência de repercussões negativas.

\section{Percepção da mulher sobre o seu corpo após a cirurgia}

A mulher se vê modificada grotescamente pela mastectomia, de forma que sua imagem corporal passa por uma enorme modificação, uma vez que essa cirurgia representa a mutilação do corpo passando para essas mulheres um sentimento de perda que pode até interferir na sua vida cotidiana (Oliveira, Fernandes, \& Galvão, 2005). Tem-se que:

"Eu tenho vergonha nossa, totalmente eu fico com vergonha de me olhar, entendeu? Então eu acho isso ai, eu fico querendo que isso acabe logo, pra ver se eu posso vestir de novo porque pra uma mulher não é fácil ver que do lado dela não tem uma mama né; a mulher já é vaidosa em si". (Orquídea)

Esse depoimento revela a primeira grande dificuldade enfrentada pelas mulheres após uma mastectomia que é a sua própria aceitação devido ao caráter simbólico atribuído ao seio representante da feminilidade, a mastectomia acarreta na mulher um sentimento de perda que degrada a identidade feminina após a cirurgia. Nesse sentido, enfatiza-se que:

"[...] eu senti assim... completamente que tirou um pedaço de mim, uma coisa um sentimento de perda. [...] eu adorava usar decotes, porém agora não posso mais [...]". (Flor de Liz)

Sendo a mama, um órgão externo, constitui uma identidade específica da mulher, e sua perda pode ser entendida como uma desfiguração e leva a mulher a não gostar de si e achar-se desinteressante, e percebendo-se desta maneira, ela pode passar a acreditar que a sociedade também a visualiza desta forma, consequentemente ela começa a fechar-se no seu mundo, com medo de encarar a si e aos outros (Rzeznik \& Dall'Agnol, 2008). Esse aspecto é representado nos seguintes depoimentos:

"A gente tem o constrangimento de tá faltando a mama, né?" (Begônia)

"Mesmo a gente com pensamento positivo, na hora de vestir uma blusa não deixa de ficar triste com a situação". (Violeta)

A identificação da mutilação se dá pela percepção da assimetria do corpo e pela visibilidade da cirurgia, o que para muitas, é um momento agressivo à sua autoimagem (Ferreira \& Mamede, 2003).

Outras mulheres, ao contrabalancear o risco de vida em virtude do câncer e a questão corporal relacionada ao significado da mama como órgão representativo da feminilidade, de modo a deixar claro que a preservação da vida fala mais alto que a questão estética. Isso é observado no seguinte depoimento:

"Pra mim, não aconteceu nada, está normal, está tudo bem. Encarei o tratamento com naturalidade, para mim a única diferença foi à falta do seio, mas foi tudo bem". (Cravo)

Mudança na vida afetiva e sexual: sentimentos e percepções

Segundo Prado (2002), observou-se em um estudo realizado em Cingapura com 20 
mulheres mastectomizadas que, dentre a totalidade das participantes, nove apresentaram problemas no relacionamento conjugal, como a diminuição na frequência de relações sexuais. Houve também mudanças no comportamento sexual, em que as mulheres evitavam se despir diante dos parceiros e for tocada pelos mesmos. A utilização de camisas durante as relações sexuais também foram relatadas pelas pacientes. Algumas mulheres relataram, ainda, que ao retomar a sua vida sexual, sentiram muita diferença e tinham medo do marido não aceitá-las mais.

"[...] agora na minha vida sexual mudou muito. Eu sinto vergonha, sinto vergonha de olhar pro meu corpo, morro de vergonha, eu tinha um namorado, terminei com ele por causa de vergonha, pois eu tenho vergonha nossa, totalmente eu fico com vergonha de me olhar [...]. Então eu acho isso ai, eu fico querendo que isso acaba logo, pra ver se eu posso vestir de novo porque pra uma mulher não é fácil ver que do lado dela não tem uma mama né; a mulher já é vaidosa em si então pra mim mudou bastante na minha sexual e pessoal mudou muito, muita coisa demais da conta mudou toda a minha rotina, todo dia vim fazer o tratamento foi uma mudança muito grande". (Orquídea)

"Não mudou muita coisa não, minha vida continua a mesma coisa, eu tive muita aceitação todo mundo me deu muito apoio principalmente o meu marido e assim a vida sexual continua a mesma coisa [...]. A gente tem o constrangimento de tá faltando a mama [...]. Então eu não tenho problemas na minha vida sexual, porque o meu marido não faz cobrança nem nada, ele me dá o maior apoio, porque ele quer ver o meu bem". (Begônia)

Os depoimentos corroboram com o estudo realizado por Cesnik e Santos (2012) que destaca que essa enfermidade resulta em alterações significativas na imagem corporal e na maneira como a mulher vivencia a autoestima, o toque, o cuidado e a sexualidade em seu sentido mais amplo. Assim, evidentemente, interferências na prática sexual são experimentadas desde a vergonha da falta da mama como também alterações físicas provocadas pelo tratamento de radioterapia e quimioterapia, como perda da mama, fadiga, ressecamento vaginal, dispaurenia (dor e desconforto no intercurso sexual).

$\mathrm{O}$ estudo realizado por Ferreira, Farago, Reis e Funghetto (2011) junto a uma amostra composta por três casais, cinco mulheres mastectomizadas e três homens que eram companheiros de mulheres portadoras de câncer de mama mastectomizadas, tornou-se possível abstrair que ainda que existisse uma vida sexual ativa antes do diagnóstico do câncer de mama, a doença proporciona uma desorganização do funcionamento sexual do casal. Tal fato ocorre devido ao comprometimento da autoimagem corporal, dor, fadiga, não só pelo impacto do diagnóstico, mas também, pelos efeitos adversos relacionados ao tratamento.

\section{Perda da mama: impacto da cirurgia na roti- na trabalhista da mulher}

Segundo os autores Panobianco e Mamede (2002) demonstra que a dor deste procedimento pode aumentar as dificuldades na realização das tarefas rotineiras da mulher, o que pode contribuir para o agravamento de outra dificuldade pós-mastectomia: ter que permanecer em casa, que contribui para o aumento da ansiedade e do sentimento de solidão, dificultando o tratamento, conforme as falas das entrevistadas: 
"A minha vida continua a rotina, a única que não gostei foi que fiquei afastada da escola e vivei com um período que eu queria voltar a trabalhar". (Rosa)

"[...] eu trabalhava agora não posso trabalhar mais [...]". (Girassol)

O estudo realizado por Ferreira e Mamede (2003) evidenciou que as mulheres participantes se encontravam, no período que antecedeu à doença, com pouca espontaneidade e muitas vezes desempenhando de forma inadequada seus papéis sociais, já que assumiam diversos papéis e se sobrecarregavam de trabalho sendo que após o descobrimento do câncer tiveram que abandonar emprego para realizar o tratamento.

\section{Repercussão e representação da família na vida da mulher mastectomizada}

Ao ser diagnosticado com o câncer de mama, a mulher precisará do apoio familiar, e é necessário que a família não esqueça suas próprias necessidades, sendo solidária, não permitindo que a paciente se deixe vencer pela doença. $\mathrm{O}$ afeto familiar permite à mulher manter certo equilíbrio para o enfrentamento contra a doença por meio do apoio emocional favorecendo uma melhor aceitação da doença e da cirurgia e orientação comportamental (Almeida, 2006).

Apesar do impacto que uma doença como o câncer de mama causa nas pessoas, observou-se, nas famílias, a presença de relações afetuosas, uma maior segurança na união, buscando um melhor enfrentamento do problema, como ilustrado a seguir:

"Ai como eu já to com alguns problemas de saúde, para eu entrar em depressão eu ia arrumar mais um problema de saúde pra mim, e ia tomar mais remédio e ia complicar tanto a minha vida e como a vida dos meus filhos, e de amigos que

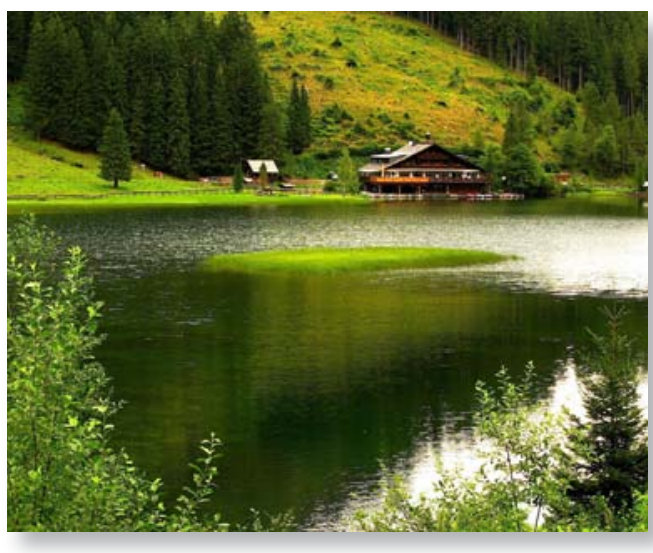

gosta muito de mim”. (Rosa)

"Oh, na minha vida familiar eu acho que assim não mudou muita coisa, assim mudou que a minha família ficou mais unida, me apoia muito na minha vida familiar". (Orquídea)

"Em relação à família, a família $e$ aproximou mais e ficou mais assim afetiva, me deu todo apoio". (Flor de Liz)

"Na vida familiar é assim, ouve mais a família se aproximar mais, teve mais aproximação, mais carinho, voltaram-se mais as atenções comigo enfim, não teve nada desagradável, tipo assim". (Copo de Leite)

Desta forma, o apoio conjugal e familiar faz-se necessário e é salutar para o enfrentamento da doença, já que o homem e a mulher se ajudam mutualmente, amenizando os flagelos decorrentes da enfermidade.

\section{Quimioterapia: enfrentamento da mulher} na superação da doença

É cada vez mais comum a indicação de quimioterapia anti-neoplásica para o câncer de mama, por ser considerado uma doença sistêmica (Jesus \& Lopes, 2003). A quimioterapia, então, principalmente por seus efeitos colaterais, é outra dificuldade que muitas mulheres mastectomizadas precisam enfrentar. A 
quimioterapia associada à mastectomia potencializa a possibilidade de sobrevida da mulher, porém pode comprometer sua qualidade de vida, uma vez que ela se sente amedrontada, abalada e insegura, diante da vivência de efeitos colaterais, os quais geralmente são agressivos tanto no plano físico quanto no psicológico (Jesus \& Lopes, 2003; Camargo \& Souza, 2000; Silva, 2008).

Para algumas mulheres mastectomizadas, a alopecia, um dos efeitos colaterais do tratamento quimioterápico, pode trazer maior sofrimento do que a própria mastectomia já que, no contexto social, a perda do cabelo mostra o diferente, o não belo, a pessoa inquestionavelmente adoecida, reforçando o sentimento de compaixão sentido pelos outros e pela própria mulher (Jesus \& Lopes, 2003), pois é cultural que o gênero feminino exiba cabelos longos e bonitos, fato que dificulta a aceitação da alopecia tanto pela mulher quanto pela sociedade.

"[...] com medo de ficar sem cabelo [...]". (Lírio)

"[...] Como vocês observa aí, o tratamento é cruel [...]. É um tratamento que veio primeiro, a quimioterapia, que eu acho que é a pior fase e depois veio a cirurgia, a radioterapia, mas eu tô encarando isso com muita força”. (Violeta)

"[...] só quando eu comecei a quimioterapia que o cabelo começou a cair, assim no primeiro momento eu achava estranho, mas, depois eu tive força [...]." (Copo de Leite)

A vivência do tratamento, seja a cirurgia ou a quimioterapia, é dolorosa e causa ansiedade e medo. Mesmo assim, as participantes não deixaram de reconhecer os danos e prejuízos colaterais que esse mesmo tratamento - que pode contribuir para curar e prevenir pode acarretar ao organismo. Elas se queixam dos efeitos adversos: os enjoos, as queimaduras na pele decorrentes da radioterapia, a queda do rendimento funcional, dentre outros. A quimioterapia foi considerada pela maioria das participantes como o pior procedimento pelo qual passaram, enquanto a radioterapia foi considerada a modalidade mais fácil de ser realizada e enfrentada.

\section{Conforto espiritual}

A devoção auxilia no enfrentamento de situações de angústia, depressão e medo, que, por sua vez, proporciona apoio e proteção. $\mathrm{O}$ sofrimento psíquico experimentado pela mulher que vivencia a mutilação pode variar de acordo com o tempo e a capacidade individual de cada pessoa, que adquire o câncer de mama. A descoberta do diagnóstico favorece a sensação de incerteza do prognóstico, com o pavor da morte. Em paralelo, podem surgir a esperança e a fé, bem como meios que auxiliem no combate a doença (Cavalcanti \& Coelho, 2007).

Essa categoria reflete a busca de conforto espiritual que auxilia na aproximação das entrevistadas na fé em Deus, sendo este quem as acompanha e consola durante todos os momentos, pois, para elas, é o único capaz de promover o alívio do sofrimento e a cura das enfermidades.

"Com a cabeça ruim [...], mas graças a Deus, agora eu já estou mais comportada, mas só me sinto assim [...] quando eu [...] olho [...] pra mim [...] eu acho [...] tão esquisito de modo que fica assim. Ave Maria! Não sei não". (Tulipa)

"Eu não tive nenhum problema não, graças a Deus [...]. Eu sou uma pessoa muito temente a Deus e Deus tem me fortalecido muito, [...], não teve nada para eu ficar cabisbaixa ou dizer [...]: 
Há como foi ruim! Não é que foi ruim, [...] foi a melhor coisa ter descoberto [...] quanto antes pra poder resolver, tratar [...]. Eu estou me sentindo bem, ótima. A gente sente falta, [...] porque tem um corpo completo [...], esteticamente a gente sente falta. Psicologicamente [...]: Ai meu Deus, como a gente vai ficar sem a mama! Pra mim não, isso não, tranquilo. Eu penso que Deus faz a gente perfeito [...]. Então, qualquer uma das partes que vem acontecer isso eu acredito que eu sou muito religiosa, creio que e permissão do Senhor e pra mim foi tranquilo até o momento [...]". (Copo de Leite)

"Mas Deus ajuda que com a fé em Deus eu vou em frente". (Gerânio)

Estes relatos demonstram que o amparo espiritual é responsável por gerar sentimentos positivos para estas mulheres, tais como: força e coragem para superar os obstáculos; confiança, apoio e consolo para amenizar o sofrimento e enfrentar momentos difíceis.

Estes depoimentos esboçam uma sensação de conforto e alívio devido à confiança e fé em Deus, pois, para estas mulheres, a fé ajuda a reerguer as suas vidas, a aceitar a sua nova condição, enfrentar as dificuldades e também a sempre tirarem uma visão positiva das coisas. É necessária a compreensão dessa teia de significados religiosos por todos os envolvidos neste processo de adoecimento, pois essa compreensão pode sinalizar uma promoção em saúde que invista na desconstrução de situações geradoras de sentimentos negativos nestas pacientes, possibilitando a elas mais coragem para lidar com a doença como algo passível de controle, assegurando maior estabilidade emocional.

Portanto, devemos estar cientes do impacto das crenças religiosas sobre a doença, pois muitas vezes a espiritualidade faz parte da saúde de um indivíduo. Assim, as pessoas que sentem Deus em sua vida são capazes de adaptar-se a mudanças inesperadas como o câncer, denunciando a crença dessas mulheres em um ser supremo.

\section{CONSIDERAÇOES FINAIS}

Este trabalho buscou enriquecer a compreensão da mulher mastectomizada, considerando, além dos aspectos biológicos, as práticas preventivas e curativas com vistas à sua reinserção social, pois o câncer traz consigo mudanças nos aspectos físicos, emocionais e sociais dos clientes.

Os depoimentos colhidos revelaram que essas mulheres passaram por diferentes períodos de adaptação psicobiológica até aceitarem a doença A revolta por ter que vivenciar uma situação inexplicável até então, trouxe perturbações e preocupações. Algumas tiveram medo de morrer quando descobriram a doença, mas os conhecimentos que adquiriram ao longo do tratamento ajudaram-nas a superar esses impasses.

A identificação da mutilação foi dada pela percepção da assimetria do corpo e pela visibilidade da cirurgia, o que para muitas, é um momento agressivo à sua autoimagem. Já para outras o tratamento foi encarado com naturalidade e relata não ter havido mudanças na sua percepção.

A vida sexual foi relatada de modo diferente entre as mulheres, as mulheres solteiras e divorciadas o impacto foi maior levando-as a ter vergonha do seu próprio corpo e se afastando de seus namorados; já as que mantinham um relacionamento estável conseguiram manter a sua vida sexual com mais tranquilidade, pois tinham o apoio de seus companheiros.

O tratamento por ser agressivo e limitador leva essas mulheres a deixarem o trabalho e 
até a realizarem tarefas rotineiras que exigem o esforço dos seus braços. Deixando-as então ociosas e se sentindo inválidas. A família foi de suma importância, pois além de ficar mais unida representou a base para essas mulheres buscarem alternativas para se curarem.

Mesmo sendo um tratamento que potencializa e aumenta a sobrevida das mulheres, a quimioterapia foi relatada como a fase do tratamento mais difícil, uma vez que as deixavam mais vulneráveis, com sentimento de mal estar e principalmente pela perda do cabelo. O amparo espiritual é responsável por gerar sentimentos positivos para estas mulheres, tais como: força e coragem para superar os obstáculos; confiança, apoio e consolo para amenizar o sofrimento e enfrentar momentos difíceis, este estava presente em todas as mulheres entrevistadas.

Portanto, é perceptível que as repercussões advindas do diagnostico da doença para as mulheres são, em sua maioria, vivenciadas de forma negativa. Porém, a possibilidade de cura e a prevenção da recidiva foram os principais argumentos utilizados pelas participantes deste estudo para justificarem a correção do tratamento realizado. Pois, a vontade de estar curada prevaleceu uma vez que a retirada da mama representava somente a retirada de um problema que estava em seu corpo.

\section{REFERÊNCIAS}

- Adachi, K., Ueno, T., Fujioka, T., Fujitomi, Y., Ueo, H. (2007). Psychosocial factors affecting the therapeutic decision-making and postoperative mood states in Japanese breast cancer patients who underwent various types of surgery: body image and sexuality. Japanese Journal of Clinical Oncology, 37(6), 412-418. Disponível em http:// www.ncbi.nlm.nih.gov/pubmed/17513308

- Almeida, R. A. (2006). Impacto da mastectomia na vida da mulher. Revista da SBPH, 9(2), 99-113. Disponível em http://pepsic.bvsalud.org/pdf/rsbph/v9n2/v9n2a07.pdf

- Amâncio, V. M., \& Costa, N. S. S. (2007). Mulher mastectomizada e sua imagem corporal. Revista Baiana de
Enfermagem, 21(1), 41-53. Disponível em http://www. portalseer.ufba.br/index.php/enfermagem/article/viewFile/3911/2880

- Barbosa, R. C. M., Ximenes, L. B., \& Pinheiro, A. K. B. (2004). Mulher mastectomizada: desempenho de papéis e redes sociais de apoio. Acta Paulista de Enfermagem, 17(1), 18-24. Disponível em http://pesquisa.bvsalud.org/ enfermagem/resource/pt/bde-11850

- Bardin, L. (2010). Análise de conteúdo. Lisboa: Edições 70. 281p.

- Camargo, T. C. (2000). O ex-sistir feminino enfrentando a quimioterapia para o câncer de mama: um estudo de enfermagem na ótica de Martin Heidegger. Tese de doutorado, Universidade Federal do Rio de Janeiro, Rio de Janeiro, RJ, Brasil. Disponível em http://bvsms.saude.gov. br/bvs/publicacoes/inca/ex-sistir_feminino_teresa.pdf

- Cantinelli, F. S., Camacho, R. S., Smaletz, O., Gonsales, B. K., Braguittoni, E., \& Rennó Junior, J. (2006). A oncopsiquiatria no câncer de mama - considerações a respeito de questões do feminino. Revista de Psiquiatria Clínica, 33(3), 124-133. Disponível em: http://www.scielo.br/ pdf/rpc/v33n3/a02v33n3.pdf

- Cavalcanti, A. C. D.,\& Coelho, M. J. (2007). A linguagem como ferramenta do cuidado do enfermeiro em cirurgia cardíaca. Escola Anna Nery Revista de Enfermagem, 11(2), 220-226. Disponível em http://www.scielo.br/pdf/ ean/v11n2/v11n2a06.pdf

- Cesnik, V. M., \& Santos, M. A. (2012). Mastectomia e sexualidade: uma revisão integrativa. Psicologia: Reflexão e Crítica, 25(2), 339-349. Disponível em http://www. scielo.br/pdf/prc/v25n2/a16v25n2.pdf

- Duarte, T. P., \& Andrade, A. N. (2003). Enfrentando a mastectomia: análise dos relatos de mulheres mastectomizadas sobre questões ligadas à sexualidade. Estudos de Psicologia, 8(1), 155-163. Disponível em http://www. scielo.br/pdf/epsic/v8n1/17245.pdf

- Ferlay, J., Shin, H. R., Bray, F., Forman, D., Mathers, C., \& Parkin, D. M. (2010). Estimates of worldwide burden of cancer in 2008: GLOBOCAN 2008. International Journal of Cancer, 127(12), 2893-2917. Disponível em http:// www.ncbi.nlm.nih.gov/pubmed/21351269

- Filgueiras, M. S. T., Lisboa, A. V., Macedo, R. M., Paiva, F. G., Benfica, T. M. S., \& Vasques, V. A. (2007). Avaliação psicossomática no câncer de mama: proposta de articulação entre os níveis individual e familiar. Estudos de Psicologia, 24(4), 551-569. Disponível em http://www. scielo.br/pdf/estpsi/v24n4/v24n4a14.pdf

- Ferreira, D. B., Farago, P. M., Reis, P. E. D., \& Funghetto, S. S. (2011). Nossa vida após o câncer de mama: percepções e repercussões sob o olhar do casal. Revista Brasileira de Enfermagem, 64(3), 536-544, 2011. Disponível em http://www.scielo.br/pdf/reben/v64n3/v64n3a18.pdf

- Ferreira, M. L. S. M., \& Mamede, M. V. (2003). Representação do corpo na relação consigo mesma após mastectomia. Revista Latino-Americana de Enfermagem, 11(3), 299-304. Disponível em http://www.scielo.br/pdf/rlae/ v11n3/16538.pdf 
- Instituto Nacional do Câncer. Coordenação Geral de Ações Estratégicas. Coordenação de Prevenção e Vigilância. (2011). Estimativa 2012: incidência do câncer no Brasil. Rio de Janeiro: INCA. Disponível em http:// portal.saude.sp.gov.br/resources/ses/perfil/gestor/homepage/estimativas-de-incidencia-de-cancer-2012/estimativas_incidencia_cancer_2012.pdf

- Instituto Nacional de Câncer. Coordenação Geral de Ações Estratégicas. Coordenação de Prevenção e Vigilância. (2009). Estimativa 2010: incidência de câncer no Brasil. Rio de Janeiro: INCA. Disponível em http://www2.inca.gov.br/wps/wcm/connect/ c1755a004eb694838c939ef11fae00ee/encarte_especial. pdf?MOD=AJPERES

- Jemal, A., Siegel, R., Xu, J., \& Ward, E. (2010). Cancer statistics, 2010. CA: A Cancer Journal for Clinicians, 60(5), 277-300. Disponível em http://www.ncbi.nlm.nih.gov/ pubmed/20610543

- Jesus, L. L. C., \& Lopes, R. L. M. (2003). Considerando o câncer de mama e a quimioterapia na vida da mulher. Revista Enfermagem UERJ, 11(2), 208-211. Disponível em http://www.facenf.uerj.br/v11n2/v11n2a14.pdf

- McGaughey, A. (2006). Body image after bilateral prophylactic mastectomy: an integrative literature review. Journal of Midwifery \& Women's Health, 51(6), 45-49. Disponível em http://www.ncbi.nlm.nih.gov/pubmed/17081926

- Moreira, H., Silva, S., \& Canavarro, M. C. (2010). The role of appearance investment in the adjustment of women with breast cancer. Psycho-Oncology, 19(9), 959-966. Disponível em http://www.ncbi.nlm.nih.gov/ pubmed/19862682

- Oliveira, M. S., Fernandes, A. F. C., \& Galvão, M. T. G. (2005). Mulheres vivenciando o adoecer em face do câncer cérvico-uterino. Acta Paulista de Enfermagem, 18(2), 150-155. Disponível em http://www.scielo.br/pdf/ape/ v18n2/a06v18n2.pdf

- Panobianco, M. S., \& Mamede, M. V. (2002). Complicações e intercorrências associadas ao edema de braço nos três primeiros meses pós mastectomia. Revista Latino-Americana de Enfermagem, 10(4), 544-551. Disponível em http://www.scielo.br/pdf/rlae/v10n4/13367.pdf

- Prado, J. A. F. A. (2002). Supervivência: novos sentidos na vida após a mastectomia. Dissertação de mestrado, Universidade Federal de Santa Catarina, Florianópolis, SC, Brasil. Disponível em https://repositorio. ufsc.br/bitstream/handle/123456789/83955/186562. pdf? sequence $=1$

- Rzeznik, C., \& Dall'Agnol, C. M. (2000). (Re)descobrindo a vida apesar do câncer. Revista Gaúcha de Enfermagem, 21(esp), 84-100. Disponível em: http://seer.ufrgs. br/index.php/RevistaGauchadeEnfermagem/article/ view/4329/2287

- Sabiston, C. M., Rusticus, S., Brunet, J., McDonough, M. H., Hadd, V., \& Hubley, A. M., et al. (2010). Invariance test of the multidimensional body self-relations questionnaire: do women with breast cancer interpret this measure differently? Quality of Life Research, 19(8), 1171-1180. Disponível em http://www.ncbi.nlm.nih. gov/pubmed/20549369

- Sánchez, R. B. (2010). Imagen corporal femenina y sexualidad en mujeres con cáncer de mama. Index de Enfermería, 19(1), 24-28. Disponível em http:// scielo.isciii.es/scielo.php?script=sci_arttext\&pid $=$ S1132-12962010001100005

- Santos, V. L. C. G., \& Sawaia, B. B. (2000). The pouch mediating the relation between" being an ostomized person" and" being professional": analysis of a pedagogic strategy. Revista Latino-Americana de Enfermagem, 8(3), 40-50. Disponível em http://www.scielo.br/pdf/rlae/ v8n3/12398.pdf

- Sebastián, J., Manos, D., Bueno, M. J., \& Mateos, N. (2007). Imagen corporal y autoestima en mujeres con cáncer de mama participantes en un programa de intervención psicosocial. Clínica y Salud, 18(2), 137-161. Disponível em http://www.copmadrid.org/webcopm/ publicaciones/clinica/105343.pdf

- Silva, R. C. S., \& Hortale, V. A. (2012). Rastreamento do câncer de mama no Brasil: Quem, Como e Por quê? Revista Brasileira de Cancerologia, 58(1), 67-71. Disponível em http://www1.inca.gov.br/rbc/n_58/v01/pdf/10b_artigo_opiniao_rastreamento_cancer_mama_brasil_ quem_como_por_que.pdf

- Silva, L. C. (2008). Câncer de mama e sofrimento psicológico: aspectos relacionados ao feminino. Psicologia em Estudo, 13(2), 231-237. Disponível em http://www. scielo.br/pdf/pe/v13n2/a05v13n2.pdf 